\section{A defasciculating dose of d-tubocurarine causes resistance to succinylcholine dose of d-tubocurarine}

Forty-four patients, ASA physical status I or II, undergoing thiamylal, fentanyl, $\mathrm{N}_{2} \mathrm{OlO}_{2}$ anaesthesia were studied to determine the dose-response to succinylcholine (Sch) without prior defasciculation (24 pt-Group 1), or three minutes following d-tubocurarine (dTC), $0.043 \mathrm{mg} \cdot \mathrm{kg}^{-1}$ (20 pt-Group 2). The individual log dose-logit response curve for each patient was determined using a cumulative dose plus infusion technique and integrated EMG monitoring of the first dorsal interosseous muscle. The mean ( $\pm S E M$ ) $E D_{50}, E D_{90}$ and $E D_{95}$ values for Sch in Group I were 0.13 $\pm 0.01,0.19 \pm 0.01$ and $0.22 \pm$ $0.01 \mathrm{mg} \cdot \mathrm{kg}^{-1}$, and in Group 2 were $0.16 \pm 0.01,0.25 \pm 0.01$ and $0.29 \pm 0.02 \mathrm{mg} \cdot \mathrm{kg}^{-1}$, respectively. The mean $E D$ values in Group 2 were significantly greater than the equivalent values in Group $1(P<0.05)$. Compared with values in Group $1, E D$ values in Group 2 represented mean increases of 23, 32, and 32 per cent, respectively. These pharmacodynamic data indicate that the dose of Sch needs to be increased by 32 per cent following a defasciculating dose of dTC $3 \mathrm{mg} \cdot 70 \mathrm{~kg}^{-1}(0.043$ $m g \cdot k g^{-1}$ ).

Lors d' une anesthésie au thiamylal, fentanyl et $\mathrm{N}_{2} \mathrm{O}$, nous avons évalué la courbe dose-réponse de la succinylcholine (Sch) de 24 patients sans précurarisation (groupe l) et celle de 20 autres, trois minutes après l'injection de $0.043 \mathrm{mg} \cdot \mathrm{kg}^{-1}$ de d-tubocurarine (groupe 2). Les mesures individuelles combinaient le

\section{Key words}

INTERACTIONS (DRUG): neuromuscular relaxants; NEUROMUSCULAR RELAXANTS: d-tubocurarine, succinylcholine.

From the Departments of Anesthesiology, Mount Sinai School of Medicine of the City University of New York, and Long Island Jewish Medical Center, New York*.

Address correspondence to: Dr. J.B. Eisenkraft, Department of Anethesiology, Box 1010, The Mount Sinai Hospital, One Gustave L. Levy Place, New York, NY, 10029-6574 U.S.A.

This work was presented in part at the Annual Meeting of the American Society of Anesthesiologists, San Francisco, CA, October 1988.
James B. Eisenkraft MD MRCP FFARCS, Melinda L. Mingus MD, Andrew Herlich DMD MD, W. Jeffrey Book MD FRCPC, Aaron F. Kopman MD* logarythme de la dose cumulative (infusion continue) au logit de la dépression de l'EMG du premier muscle interosseux dorsal. Les $D E_{50}, D E_{90}$ et $D E_{95}$ (moyenne \pm erreur-type) de la Sch étaient respectivement dans le groupe $I$ de $: 0,13 \pm 0,01,0,19$ $\pm 0,01$ et $0,22 \pm 0,01 \mathrm{mg} \cdot \mathrm{kg}^{-1}$ alors que dans le groupe 2 elles étaient de :0,16 $\pm 0,01,0,25 \pm 0,01$ et $0,29 \pm 0,02$, supérieures donc à celles du groupe $I$ de 23, 32 et 32 pour cent respectivement $(P<0,05)$. Grâce à cette étude pharmacodynamique, on voit qu' il faut augmenter la dose de Sch de 32 pour cent si on la fait précéder d'une dose de $3 \mathrm{mg} \cdot 70 \mathrm{~kg}\left(0,043 \mathrm{mg} \cdot \mathrm{kg}^{-1}\right)$ de d-tubocurarine.

The clinical dose of a muscle relaxant is usually selected on the basis of the effective dose (ED). Thus an $E D_{90}$ dose or multiple thereof would be administered to achieve relaxation for tracheal intubation. The $\mathrm{ED}_{90}$ for succinylcholine (Sch) is $0.22-0.30 \mathrm{mg} \cdot \mathrm{kg}^{-1}$ and the commonly used intubating dose is therefore three to five times this value. 1

The administration of Sch is often preceded by a small dose of d-tubocurarine (dTC), which may prevent some of the undesirable side effects of Sch. Previous studies have suggested that the onset of relaxation produced by Sch is delayed and that the intensity and duration of relaxation are decreased following a defasciculating dose of dTC, but that adequate relaxation can be restored by increasing the usual dose of Sch by $25-75$ per cent. ${ }^{2-5}$ Bevan et al. ${ }^{6}$ have recommended the use of Sch in a dose of $1 \mathrm{mg} \cdot \mathrm{kg}^{-1}$ when given alone, and $1.5 \mathrm{mg} \cdot \mathrm{kg}^{-1}$ when preceded by dTC. While previous studies have addressed the effect of dTC on the times to onset and offset of action of Sch, other than in terms of intubating conditions, the effect on the intensity of block has not been well documented. The purpose of this study was to document the effect of a small commonly used clinical dose of $\mathrm{dTC}, 3 \mathrm{mg} \cdot 70 \mathrm{~kg}^{-1}$, on the dose-effect relationship of subsequently administered Sch.

\section{Methods}

Forty-four adult patients, ASA physical status I or II, scheduled to undergo elective orthopaedic or gynaecolog- 
ical surgery gave written informed consent to participate in this institutionally approved study. All were free from drugs or conditions known to affect neuromuscular function. All patients received diazepam, $5-10 \mathrm{mg} \mathrm{PO}$, as premedication prior to arrival in the operating room. Arterial blood pressure (Dinamap ${ }^{\circledR}$ ), electrocardiogram and arterial haemoglobin oxygen saturation by pulse oximetry were continuously monitored in all cases. Anaesthesia was induced with thiamylal sodium, 3-5 $\mathrm{mg} \cdot \mathrm{kg}^{-1}$ and maintained with nitrous oxide 66 per cent in oxygen. Supplemental doses of thiamylal 0.5-1.0 $\mathrm{mg} \cdot \mathrm{kg}^{-1}$, and fentanyl, $1-2 \mu \mathrm{g} \cdot \mathrm{kg}^{-1}$, were administered as required. Ventilation was assisted using a bag and facemask to maintain end-tidal $\mathrm{CO}_{2}$ within normal range (30-35 $\mathrm{mmHg}$ ) as measured by mass spectrometry (Perkin Elmer Advantage 1100, Pomona, CA). Potent inhaled volatile anaesthetic agents were not used during the period of this study.

Neuromuscular transmission was assessed using an integrated EMG monitor (Datex NMT Monitor 221, Puritan Bennett, Wilmington, MA). Once the patient was anaesthetized as described above, supramaximal trainsof-four stimuli ( $2 \mathrm{~Hz}$, stimulus duration $0.1 \mathrm{msec}$ ) were applied every ten seconds via surface electrodes to the ulnar nerve at the wrist and the baseline integrated EMG responses of the first dorsal interosseous muscle were recorded continuously. Following stabilization of the EMG response, the monitor was recalibrated to read a baseline EMG response of 100 per cent. At this time, 24 patients (Group 1) received no d-tubocurarine (dTC), while 20 patients (Group 2) received dTC $3 \mathrm{mg} \cdot 70 \mathrm{~kg}^{-1}$ $\left(0.043 \mathrm{mg} \cdot \mathrm{kg}^{-1}\right)$. Three minutes later all patients received Sch $0.10 \mathrm{mg} \cdot \mathrm{kg}^{-1}$ IV followed by incremental doses of $0.05 \mathrm{mg} \cdot \mathrm{kg}^{-1}$ together with an infusion of Sch, the rate of which was adjusted to replace eliminated drug. ${ }^{7}$ Incremental doses were given and the infusion rate increased when two consecutive equal first responses $\left(T_{1} / C\right)$ were observed in the continuously recorded EMG tracing. This cumulative dose plus infusion technique and the calculation of the rate of infusion needed with each incremental dose are described in detail elsewhere. ${ }^{7}$ Based upon the work of Smith et al. ${ }^{7}$ it was assumed that if a given bolus dose of Sch produced a certain amount of depression $T_{1} / C$ response, then an infusion rate of 15 times this dose per hour would be required to maintain that same level of $T_{1} / C$ depression. Thus, following an initial bolus dose of $\mathrm{Sch}, 0.10 \mathrm{mg} \cdot \mathrm{kg}^{-1}$, when the $T_{1} / \mathrm{C}$ decrement had been stable for 20-30 seconds (three equal consecutive $T_{1} / C$ responses), an incremental bolus dose of Sch $0.05 \mathrm{mg} \cdot \mathrm{kg}^{-1}$ was given and an infusion of $(15 \times$ $0.10) \mathrm{mg} \cdot \mathrm{kg}^{-1} \cdot \mathrm{hr}^{-1}$ was commenced. With the administration of a further incremental bolus dose of Sch 0.05 $\mathrm{mg} \cdot \mathrm{kg}^{-1}$, the infusion rate was increased to $15 \times 0.15$ $\mathrm{mg} \cdot \mathrm{kg}^{-1} \cdot \mathrm{hr}^{-1}$. Additional bolus doses of Sch and infusion rate increases were continued until a 95-99 per cent decrease in $T_{1} / C$ had been achieved. At this time the trachea was intubated and the lungs were ventilated using an anaesthesia ventilator.

Regression analyses (least squares) were performed for each patient data set between the logit transformation of neuromuscular blockade (defined as percentage decrease in $T_{1} / C$ ) and the logarithm of the cumulative dose of Sch. Only the doses given in bolus form were considered in the calculation of the dose-response curves because the amount given by infusion was to compensate for drug which had been eliminated. 'From the individual doseresponse curves, a mean dose-response curve was constructed for each group and from these the doses producing 50,90, and 95 per cent block $\left(E D_{50}, E D_{90}\right.$, and $\mathrm{ED}_{95}$ ) were calculated. The group mean slopes, intercepts and ED values were compared using a Student's t test for unpaired data. The ED results are expressed as group means together with 95 per cent confidence limits. A difference in ED values between the two groups was considered to be significant if $P$ was less than 0.05 .

\section{Results}

Patient demographic data are summarized in Table $\mathbf{I}$. No significant differences were found between the two groups in mean age or weight. In Group 2, three minutes following dTC the mean \pm SD decrease in $T_{1} / C$ was 5.3 \pm 4.4 per cent. Each patient received between three and seven doses of Sch and the total duration of the study period in each patient was generally less than five minutes.

The mean dose-response curves derived from the individual patient data are depicted in the Figure. The curve for Group 2 (defasciculated) was to the right of that of Group 1. While no significant difference in slopes was found $(P=0.20)$, there was a significant difference in intercepts $(P<0.05)$. There were significant differences between the two groups in the $\mathrm{ED}_{50}, \mathrm{ED}_{90}$ and $\mathrm{ED}_{95}$ values derived from these mean curves (Table II). The mean $\mathrm{ED}_{50}, \mathrm{ED}_{90}$ and $\mathrm{ED}_{95}$ values in the defasciculated patients, Group 2, were $0.16,0.25$ and $0.29 \mathrm{mg} \cdot \mathrm{kg}^{-1}$,

TABLE I Demographic data

\begin{tabular}{lll}
\hline & $\begin{array}{l}\text { Group 1 } \\
\text { Sch } \\
n=24\end{array}$ & $\begin{array}{l}\text { Group 2 } \\
d T C+\text { Sch } \\
n=20\end{array}$ \\
\hline Males/females & $3 / 21$ & $4 / 16$ \\
Age (yr) & $37 \pm 9$ & $37 \pm 8$ \\
Weight (kg) & $65 \pm 12$ & $62 \pm 9$ \\
\hline
\end{tabular}

Values are given as mean $\pm S D$. 


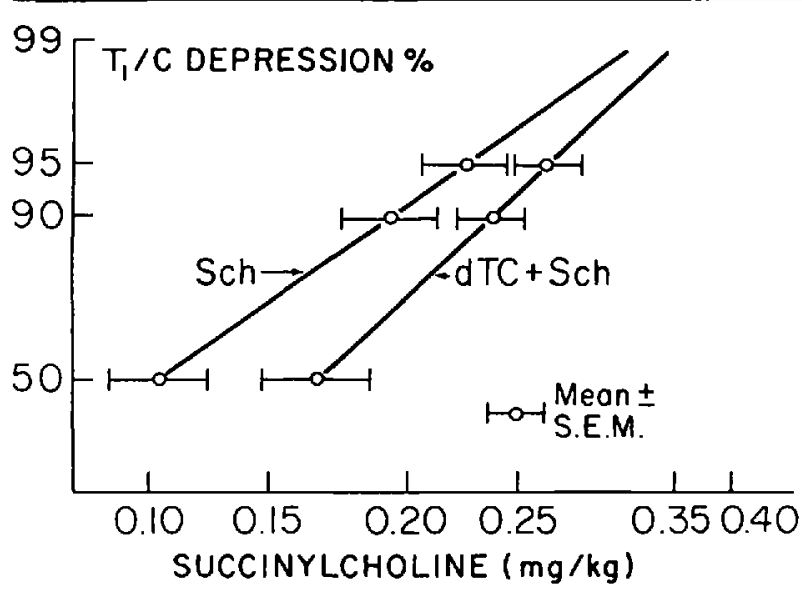

FIGURE Mean dose-response relationships for Sch administered alone and following dTC $0.043 \mathrm{mg} \cdot \mathrm{kg}^{-1}$ as derived by a cumulative dose plus infusion technique. ${ }^{7}$ The logit transformation of $T_{1}$ depression per cent, as measured by integrated EMG, is plotted as a function of log cumulative dose. The lines were derived using linear regression (least squares). The equations to the lines are: Group 1 (Sch alone): logit response $=6.60 \times \log$ dose +5.48 ; Group 2 $(\mathrm{dTC}+$ Sch $)$ : logit response $=5.63 \times \log$ dose +4.35 .

compared with $0.13,0.19$ and $0.22 \mathrm{mg} \cdot \mathrm{kg}^{-1}$ in the non-defasciculated patients, Group 1, respectively. On average, defasciculation caused a 23, 32 and 32 per cent increase in $\mathrm{ED}_{50}, \mathrm{ED}_{90}$ and $\mathrm{ED}_{95}$, respectively, when compared with controls.

\section{Discussion}

A defasciculating or "precurarizing" dose of $\mathrm{d}$ tubocurarine (dTC) is commonly administered prior to succinylcholine (Sch) in order to prevent potentially undesirable effects, such as fasciculations, increased intragastric pressure, increased intraocular pressure, muscle pains and hyperkalaemia. ${ }^{8}$ An antagonism between the neuromuscular blockade produced by depolarizing and nondepolarizing relaxants was first described in 1949 in relation to dTC and decamethonium. ${ }^{9}$ Walts and Dillon ${ }^{10}$ studied the effect of dTC given three minutes before Sch and found significant reductions in both duration and intensity of the induced block. Miller and Way ${ }^{8}$ found that $S \mathrm{ch} 1.0 \mathrm{mg} \cdot \mathrm{kg}^{-1}$ always produced 100 per cent twitch height depression, even when preceded by dTC $3 \mathrm{mg}$ but that the time to 80 per cent recovery was shortened by dTC.

Cullen ${ }^{4}$ found that, when dTC $3 \mathrm{mg}$ preceded Sch 1.0 $\mathrm{mg} \cdot \mathrm{kg}^{-1}$, the onset of block was delayed, the recovery time was shorter, and tracheal intubation was more difficult compared with Sch given alone. When the dose of Sch was increased to $1.5 \mathrm{mg} \cdot \mathrm{kg}^{-1}$, intubating conditions were still not comparable with those in the control group. Freund and Rubin ${ }^{3}$ concluded that, if a $3 \mathrm{mg}$
TABLE II ED values $\left(\mathrm{mg} \cdot \mathrm{kg}^{-1}\right)$ for non-defasciculated and defasciculated patients

\begin{tabular}{|c|c|c|c|}
\hline & $\begin{array}{l}\text { Group I } \\
\text { Sch } \\
n=24\end{array}$ & $\begin{array}{l}\text { Group } 2 \\
d T C+S c h \\
n=20\end{array}$ & $P$ \\
\hline $\begin{array}{l}\mathrm{ED}_{50} \mathrm{mg} \cdot \mathrm{kg}^{-1} \\
\text { ( } 95 \text { per cent confidence }\end{array}$ & 0.13 & 0.16 & $<0.05$ \\
\hline limits) & $0.11-0.15$ & $0.14-0.19$ & \\
\hline $\begin{array}{l}\mathrm{ED}_{90} \mathrm{mg} \cdot \mathrm{kg}^{-1} \\
\text { ( } 95 \text { per cent confidence }\end{array}$ & 0.19 & 0.25 & $<0.001$ \\
\hline limits) & $0.17-0.22$ & $0.22-0.28$ & \\
\hline $\begin{array}{l}\mathrm{ED}_{95} \mathrm{mg} \cdot \mathrm{kg}^{-1} \\
\text { ( } 95 \text { per cent confidence }\end{array}$ & 0.22 & 0.29 & $<0.001$ \\
\hline limits) & $0.20-0.25$ & $0.26-0.33$ & \\
\hline
\end{tabular}

defasciculating dose of dTC is used, "then at least 70 per cent more succinylcholine must be given to ensure consistently adequate relaxation for intubation."

Commenting on the above three studies, ${ }^{3,4.8} \mathrm{Miller}^{2}$ concluded that "paralysis by Sch will be decreased when it is preceded by $3 \mathrm{mg}$ of dTC," and that, "in a $70 \mathrm{~kg}$ patient, the usual dose of Sch of about $60 \mathrm{mg}$ would have to be increased to $100 \mathrm{mg}$ " (i.e., by 66 per cent). Others have recommended Sch $1.0 \mathrm{mg} \cdot \mathrm{kg}^{-1}$ given alone, and 1.5 $\mathrm{mg} \cdot \mathrm{kg}^{-1}$ when it is preceded by dTC. ${ }^{5}$ Ferguson and Bevan ${ }^{11}$ found that dTC $3 \mathrm{mg}$, given before Sch $1.0 \mathrm{mg}$. $\mathrm{kg}^{-1}$, produced no observable difference in the intensity of the block because the twitch response was completely abolished in all but four of the 70 patients in their study. Intubating conditions were satisfactory in all of their patients, but this may have been due to their use of halothane $1.0-1.5$ per cent for up to 20 minutes prior to intubation. "1

Only one study, that of Pauca et al. ${ }^{5}$ has quantified the effect of pretreatment with dTC $3 \mathrm{mg}$ on relaxation produced by subsequently administered Sch. However, in their study, Sch was given as a constant infusion $(0.58$ $\mathrm{mg} \cdot \mathrm{sec}^{-1}$ ). In control patients (no dTC) the infusion times to achieve 50 and 90 per cent block were 34.7 and $46.0 \mathrm{sec}$, representing mean "infusion" $\mathrm{ED}_{50}$ and $E D_{90}$ values of 0.34 and $0.46 \mathrm{mg} \cdot \mathrm{kg}^{-1}$, respectively. Following a defasciculating dose of dTC $3 \mathrm{mg}, 0.051 \mathrm{mg} \cdot \mathrm{kg}^{-1}$, the mean infusion times to 50 and 90 per cent block were 46.3 and $58.3 \mathrm{sec}$, representing increases of 33 and 27 per cent in infusion times. The "infusion" $E D_{50}$ and $E D_{90}$ values of 0.45 and $0.57 \mathrm{mg} \cdot \mathrm{kg}^{-1}$, represented increases of 29 and 18 per cent over control, respectively. The ED values calculated from Pauca et al.'s infusion data are greater than those reported by others who used different methods for potency estimation. ${ }^{7,12}$ They concluded that "a recommendation that $\mathrm{dTC}$ be given to block the side-effects of Sch is made with the accompanying 
warning that 70-75 per cent more $\mathrm{Sch}$ is required for the same degree of block." 5 Others have suggested that dTC 3 mg pretreatment to prevent postoperative myalgias necessitated the use of only 25 per cent more Sch infusion to achieve comparable relaxation. ${ }^{13}$

In view of the above-described and sometimes conflicting reports on the effects of defasciculation, we sought to determine how the commonly used dose of dTC $3 \mathrm{mg}$ (per $70 \mathrm{~kg}$ ) would alter the dose-response to Sch administered three minutes later. Resistance in our study was defined as a significant increase in ED values. We used a cumulative dose plus infusion (CDI) technique to define the doseresponse relationships for $\mathrm{Sch}$. This technique has been shown to provide ED values for Sch which are essentially identical to those derived using a single dose technique, yet it offers the advantage that a complete dose-response curve can be obtained for each individual patient. ${ }^{7,12}$

Potential problems with the use of a CDI technique to develop a dose-response relationship for Sch following dTC include that, while the first dose of Sch was given three minutes following $\mathrm{dTC}$, the last was given some eight minutes after dTC. However, a pharmacokinetic model suggests that a fairly constant concentration of dTC would have been maintained in the effect compartment for the duration of the study period and therefore that the effect due to dTC should have remained constant.

Another potential problem is that the same Sch infusion rate (i.e., 15 times the cumulative dose given per hour) was used in all the cases studied and that it may have represented an excessive amount in some cases and too little in others. In the original description of the CDI technique the factor of 15 was used in each of the ten patients studied and derived ED data were essentially identical to those obtained in 18 patients in whom a single bolus technique was used. ${ }^{7}$ It is also likely that any such errors in infusion rate would have become unimportant when the mean for each group of patients was calculated.

We found that dTC $0.043 \mathrm{mg} \cdot \mathrm{kg}^{-1}$ increased the $E D_{50}$, $E D_{90}$, and $E D_{95}$ values for Sch by 23,32 and 32 per cent, respectively. This is qualitatively in agreement with results of the studies previously cited. ${ }^{2: 5,8,10}$ Quantitative differences are most likely due to differences in methodology between the present and previous studies. Thus while others have used single dose $\left(1.0 \mathrm{vs} 1.5 \mathrm{mg} \cdot \mathrm{kg}^{-1} ; 0.7 \mathrm{vs}\right.$ $\left.1.2 \mathrm{mg} \cdot \mathrm{kg}^{-1}\right)^{2,3}$ or infusion ${ }^{5}$ techniques to study the potency of Sch, we have defined the actual dose-response curves. It remains to be determined whether increasing the clinically used dose of Sch (usually $1 \mathrm{mg} \cdot \mathrm{kg}^{-1}$ ) by only 32 per cent, as is suggested by the present results, would restore to normal the onset and duration of Sch following defasciculation with dTC $3 \mathrm{mg}$.

Although the evoked mechanomyographic (MMG) response of the adductor pollicis muscle is the method whereby neuromuscular blockade is most commonly monitored, Kopman ${ }^{14}$ has reported that the first dorsal interosseous EMG may be used interchangeably with adductor pollicis $M M G$ in determining the depth of nondepolarizing neuromuscular blockade. We used integrated EMG monitoring of the first dorsal interosseous muscle because this technique is simple to apply and may also be used in patients whose arms need to be kept adducted. Furthermore, there does not appear to be an important difference between $E M G T_{1} / C$ and $M M G ~ T_{1} / C$ when studying the onset of Sch-induced blockade although the EMG has been found to be depressed slightly more than the MMG. ${ }^{15}$ However, the relationship between the two monitoring techniques is linear ${ }^{15}$ and, since the EMG was used in all of our patients, we believe that a between-group comparison is therefore valid.

The ED values presently reported for Sch in normal patients are lower than those reported previously. ${ }^{12}$ These differences are most likely due to the use of the first dorsal interosseous muscle in the present study, whereas previously the responses from the hypothenar muscles were monitored. That the first dorsal interosseous muscle may be more sensitive to the effects of non-depolarizing neuromuscular blocking drugs than are the hypothenar and adductor pollicis muscles has been suggested. ${ }^{16}$

In conclusion, we have shown by a cumulative dose plus infusion technique that the administration of dTC 3 $\mathrm{mg} \cdot 70 \mathrm{~kg}^{-1}$ significantly alters the dose-effect relationship for Sch administered three to eight minutes subsequently. Following $\mathrm{dTC}$, the $\mathrm{ED}_{50}, \mathrm{ED}_{90}$ and $\mathrm{ED}_{95}$ of Sch were increased by 23,32 and 32 per cent, respectively. Previous studies have shown that dTC $3 \mathrm{mg}$ slows the onset and speeds the offset of action of Sch, and recommendations have been to increase the Sch dose from $1.0 \mathrm{mg} \cdot \mathrm{kg}^{-1}$ to $1.5 \mathrm{mg} \cdot \mathrm{kg}^{-1}$ or by $25-75$ per cent, following dTC. If the dose of Sch required to produce good conditions for tracheal intubation is a fixed multiple of the $\mathrm{ED}_{90}$ then, based upon our results, the clinical dose of Sch should be increased by 32 per cent following defasciculation with dTC $0.043 \mathrm{mg} \cdot \mathrm{kg}^{-1}$. The mechanism whereby dTC causes resistance to subsequently administered Sch is not known, but it has been suggested that a defasciculating dose of the dTC binds to a number of the cholinergic receptors, thereby preventing Sch from reaching them. ${ }^{17}$

\section{Acknowledgements}

The authors are grateful to Mrs. Betty Perez-Rivera for administrative support. 


\section{References}

1 Cook DR. Pharmacokinetics of succinylcholine in infants, children and adults. Clin Pharmacol Ther 1976; 20: 493-8.

2 Miller $R D$. The advantages of giving d-tubocurarine before succinylcholine. Anesthesiology 1972; 37: 568-9.

3 Freund FG, Rubin AP. The need for additional succinylcholine after d-tubocurarine. Anesthesiology 1972; 36: 185-6.

4 Cullen DJ. The effect of pretreatment with nondepolarizing muscle relaxants on the neuromuscular blocking actions of succinylcholine. Anesthesiology 1971; 35: 572-8.

5 Pauca AL, Reynolds RC, Strobel GE. Inhibition of suxamethonium relaxation by tubocurarine and gallamine pretreatment during induction of anaesthesia in man. $\mathrm{Br}$ J Anaesth 1975; 47: 1067-73.

6 Bevan DR, Bevan JC, Donati F. Muscle Relaxants in Clinical Anesthesia. Chicago: Year Book Medical Publishers, Inc., 1988, 265.

7 Smith CE, Donati F, Bevan DR. Dose-response curves for succinylcholine: single versus cumulative techniques. Anesthesiology 1988; 69; 338-42.

8 Miller $R D, W a y W L$. The interaction between succinylcholine and subparalyzing doses of d-tubocurarine and gallamine in man. Anesthesiology 1971; 35: 567-71.

9 Paton WDM, Zaimis EJ. The pharmacological actions of polymethylene bistrimethylammonium salts. Br J Pharmacol 1949; 4: 381-400.

10 Walts $L F$, Dillon JB. Clinical studies of the interaction between d-tubocurarine and succinylcholine. Anesthesiology 1969; 31: 39-44.

11 Ferguson A, Bevan DR. Mixed neuromuscular block. The effect of precurarization. Anaesthesia 1981; 36: 661-6.

12 Eisenkraft JB, Book WJ, Mann SM, Papatestas AE, Hubbard M. Resistance to succinylcholine in myasthenia gravis. A dose-response study. Anesthesiology 1988; 69: 760-3.

13 Dottori $O$, Lof BA, Ygge H. Muscle pains after suxamethonium. Acta Anaesthesiol Scand 1965; 9: 247-9.
14 Kopman AF. The dose-effect relationship of metocurine: the integrated electromyogram of the first dorsal interosseous muscle and the mechanomyogram of the adductor pollicis compared. Anesthesiology 1988; 68: 604-7.

15 Weber $S$, Muravchick $S$. Electrical and mechanical trainof-four responses during depolarizing and nondepolarizing neuromuscular blockade. Ancsth Analg 1986; 65 : $771-6$.

16 Eisenkraft $J B$. The dose-cffect relationship of metocurine: EMG versus MMG. Anesthesiology 1988; 69: 807.

17 Viby-Mogensen $J$. Interactions of other drugs with muscle relaxants. In: Katz RL (Ed.). Muscle Relaxants, Basic and Clinical Aspects. Orlando: Grune \& Stratton, 1985: 241 . 